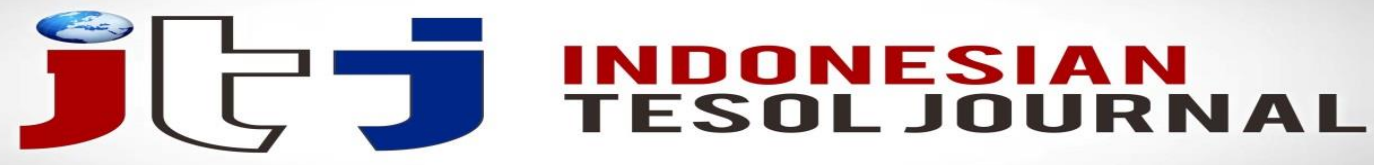

e-ISSN: 2622-5441(Online) Journal homepage: https://ejournal.iainpalopo.ac.id/index.php/ITJ/index

\title{
The Usage of Cohesive Devices by High-Achieving EFL Students in Writing Argumentative Essays
}

\author{
Andri Saputra and M. Arif Rahman Hakim \\ Institut Agama Islam Negeri Bengkulu, Indonesia
}

Abstract: This study aims to investigate types of cohesive devices frequently used in writing argumentative essays by high-achieving college students in Indonesia and to analyse their awareness of usage of these. Participants were asked to write an essay on a pre-determined topic; analysis was then conducted to investigate the most frequent cohesive devices used. Data on the second study question, understanding of the usage of cohesive devices, were gathered though semi-structured interviews. The data indicate that students effectively used various types of grammatical cohesive devices, particularly reference devices. However, some claimed not to know that they were using other cohesive devices. They believed that conjunctions were the only type that functions to connect ideas across sentences and paragraphs, and did not realise that this, that, the, and other reference devices are cohesive devices. In terms of the use of lexical cohesive devices, participants used synonyms more than other sub-types of lexical cohesive devices. The most frequently used device was the, which functions both as a cohesive device and an article. All participants agreed that though links or cohesive devices are necessary to achieve coherence, two claimed that these are not determining factors in producing good writing quality. They argued that high-quality writing needs to contain linguistic features related to sophisticated language and text difficulty. The first suggestion is that focused programs should be adopted to teach the writing of argumentative essays to help lower-achieving students attain the same writing level as high-achieving students. Second, a teaching programme integrating the use of sophisticated grammar, lexical diversity and cohesive devices should be a curriculum priority.

Keywords: Argumentative essays; Cohesive devices; High-achieving students

\section{INTRODUCTION}

Cohesive devices are words and phrases that act as signals to the readers (Reid, 1992). There is agreement amongst those dealing with the English writing of Indonesian first language (L1) users that the correct use of cohesive devices is one of the most challenging skills to develop. Enkvist (1990) deemed the attainment of cohesion in writing as an indefinable concept which is challenging to teach and learn. When learners generate written text, they must show cohesion and coherence in presenting their ideas (Halliday and Hasan, 1969). Halliday and Hasan (1969) view cohesion as one of the primary text construction resources in the linguistic system. This is in line with Alarcon and Morales (2011), who define cohesion as the linguistic features or cohesive devices which assist in making a sequence of sentences in a text, while coherence refers to the overall sense and meaning that the text imparts (Wahiba, 2017; Ghasemi, 2013). Cohesive devices are significant 
because they are used to connect pieces of discourse to create a coherent text (Halliday and Hassan, 1969). Ad ditionally, mastery of these is an important element in academic writing and crucial for success at all levels and stages of academia where English is the means of instruction (Ghasemi, 2013). Therefore, the use of cohesive devices in academic writing has drawn the attention of numerous researchers striving to understand cohesion in student writing, including in countries such as Indonesia, where English is taught as a foreign language.

\section{Argumentative essays as the focus genre for the study}

In addition to knowledge about the internal cohesive features of written texts, Dasterdi and Samian (2011) suggest that familiarity with distinct genres of writing can predispose learners' writing quality. In this study, argumentative writing is the focus. Argumentation is a type of formal academic writing common in tertiary level education. Writers are required to state a main proposition, present supporting evidence and reasons, use academic terminology and formal language, and be explicitly objective. For argumentation to be convincing, it needs to be directly presented and straightforward (Podis and Podis, 1996), and the valid premises of argument need to be observed (Raimes, 2002). This type of academic writing is very often applied in examinations and, increasingly, in course work where students are required to state and defend an opinion (Munsell and Clough, 1984). It is considered that argumentative writing is one of the most challenging styles of all, and necessary for students to master, as it is demanded in tertiary level courses and many future careers (Tate et al., 1994).

\section{Cohesion and coherence}

As noted in Introduction, learners or writers must exhibit some form of cohesion and coherence in conveying their ideas when they produce written text (Halliday and Hasan, 1967). It can be argued that there are two essential components in generating a piece of good composition, cohesion and coherence. In this section, these two concepts will be illustrated by examining views from a number of experts.

The concept of cohesion was initially introduced by Halliday and Hasan (1969) leading researchers in the field of text analysis. Halliday and Hasan (1969) posit that text has a texture that unifies it with regard to its context, and differentiates it from non-text, stating that '[i]f a passage of English containing more than one sentence is perceived as a text, there will be certain linguistic features present in that passage which can be identified as contributing to its total and giving it texture' (Halliday and Hasan, 1969:2). They also claim that cohesion refers to 'the range of possibilities that exist for linking something with what has gone before' (Halliday and Hasan, 1969:10).

Furthermore, the definitions of coherence and cohesion are clearly differentiated by Halliday and Hassan (1969) even though the authors do not provide a clear explanation of the differences. However, in general, Hassan (1984) views the concept of cohesion as 'the foundation upon which the edifice of coherence is built' (Hasan, 1984:94). Persons (1991:415) adds that cohesion is an essential feature of a text if it is to be judged to be coherent. Halliday (1984) describes the relationship between coherence and cohesion by emphasising that cohesion is a supportive textual property that helps to build coherence in order to 
understand the text as a whole. Hence, cohesion provides an essential contribution to coherence by connecting one part of the text to another.

\section{Relationship between cohesion and coherence in argumentative writing}

One of the important features of a well-written text is its connectedness and unity, so that every sentence in the text is linked (Celce-Murcia and Olstain, 2000). This textual relation is, to a degree, an outcome of the coherent organisation of the ideas and propositions presented in writing. Furthermore, this relationship notably hinges on the thorough process the writer goes through to produce grammatical and formal cohesion among sentences and paragraphs (Carter, 2001). Thus, the writer can strengthen coherence and generate overall and local unity by utilising varied devices.

On the whole, the coherence of a long text depend s on the coherence in each section or paragraph (Celce-Murcia and Olstain, 2000). In the context of argumentative writing, cohesion is needed to connect every opinion and justification, as it offers a way for grammatical features or certain words in a sentence to connect the opinion and justification (Hoey, 1991). Coherence is also an indispensable feature that connects information or ideas in different parts of the text, so that the reader can understand the whole text more easily (Celce-Murcia and Olstain, 2000). Each sentence in this type of writing is related to both previous and subsequent sentences. Moreover, the purpose and intended readers of an argumentative text also play an important role. For instance, when a reader tries to read subject-specific materials on matters such as politics, the economy, or education, they may understand the reading material more easily if they have background knowled ge of what they are reading. However, they could also possibly understand the reading material easily by following its coherence. Therefore, coherence can ensure a logical progression in a text, enabling the reader to understand it through connectedness of the propositions presented.

\section{METHODOLOGY}

This study aims to investigate two issues. The first is to identify cohesive devices most frequently used by students in argumentative essays and to examine their awareness of their use in such writing. The researcher uses mixed methods in a case study, as the first research question deals with a numerical or quantitative analysis of certain lexical and grammatical features. In other words, the researcher measures the number of times certain features occur within percentages. The next reason for such choice is the second research question, which requires a deep qualitative investigation of participants' understanding of the usage of cohesive devices. The researcher hopes to elicit student awareness of using cohesive devices in argumentative writing through interviews. Therefore, a quantitative and qualitative mixed-methods approach using a case study is considered suitable.

The mixed methods approach has been developed on the assumption that it can help to integrate the strengths of both quantitative and qualitative approaches (Lopez-Fernandez and Molina-Azorin, 2011). According to Tashakkori and Teddlie (2010), when the findings are combined, results can increase understanding of a phenomenon that would have otherwise been difficult to answer completely using a single method. Thus, on the basis of the features of the mixed quantitative 
and qualitative methods in a case study presented above, the researcher decided that these would be appropriate for the spirit of the study and the research questions.

In order to answer the two research questions the researcher decides on a small sample size, six participants from a total of 60 students majoring in teaching English in an Islamic college in Indonesia, ranging in age from 21 to 23 years old. The participants in the study are chosen randomly, although they must meet certain criteria to participate voluntarily. They should have achieved a Grade A in the College English writing course completed in semester three of their studies, during which there had been a focus on writing argumentative essays.

Participants are selected randomly, helped by a third party who works as an office administrator at the college where the participants study. Potential participants receive an email from the administrator, which explains why it is important to participate in this study. The use of a third party is a means by which the researcher can avoid bias, as the participants were the researcher's students when he taught at the college. The participants are also sent an information letter about the research and asked for their consent. Once all of these documents are returned, the collection of data on writing argumentative essays and interviews commences.

The first data collection technique used is the evaluation and analysis of students' argumentative essays. The students are asked to write argumentative essays on a common topic about which every student presumably has ideas and background knowledge (for example, Facebook). Following collection, this data is analysed to address research question 1: what types of cohesive devices are most frequently used in argumentative essays written by high-achieving EFL students.

As the participants of this study are in another country and at a distance, the researcher asks the third party to control and monitor the participants doing the writing task. The third party is an administrator who works at the college where the participants learned English. The involvement of this third party is to assist the researcher in conducting the data collection which is first, to find participants (by emailing students who might potentially be participants), monitoring the participants while they do their writing task, and sending the writing tasks to the researcher to proceed to the analysis stage.

The researcher also asks two external examiners from Indonesia, teachers from another college, to measure the students' writing tasks. The examiners have more than two years experience in teaching academic writing and do not know who the participants in this study are. It is essential to have assistance from these external examiners, as the focus of this research is to see how students who gained Grade A in an argumentative essay class can apply cohesive devices in argumentative writing. Students who obtained this grade are considered to be high-achieving students who have good writing quality. 


\section{FINDINGS AND DISCUSSION}

\section{Analysis of Texts Written by the Higher-achieving Students Conducted by the Researcher}

Students' usage of cohesive devices

The researcher undertakes this step to demonstrate the students' production of cohesive devices in their argumentative essays. The researcher also shows which of the cohesive devices are used and why some devices are more frequently used while some of them are not. In relation to each type of cohesive device used, the researcher found the following results;

Table 1. Students' usage of cohesive devices

\begin{tabular}{|c|c|c|}
\hline Types of cohesive devices & Students' cohesive devices & Usage \\
\hline Grammatical cohesive devices & $N$ & $\%$ \\
\hline 1. Reference & 166 & $57.44 \%$ \\
\hline 2. Conjunctions & 89 & $30.80 \%$ \\
\hline 3. Ellipsis & 0 & 0 \\
\hline 4. Substitution & 0 & 0 \\
\hline Total & & $80.24 \%$ \\
\hline Lexical cohesive devices & 8 & \\
\hline 1. Repetition & 13 & $2.77 \%$ \\
\hline 2. Synonyms & 9 & $4.50 \%$ \\
\hline 3. Meronyms & 4 & $3.11 \%$ \\
\hline 4. Superordinates & & $1.38 \%$ \\
\hline Total & $\mathbf{2 8 9}$ & $11.76 \%$ \\
\hline Total & & $\mathbf{1 0 0}$ \\
\hline
\end{tabular}

The percentage of cohesive devices in the table above was obtained by using the following formula:

$$
P=\frac{N}{T} \times 100 \%
$$

$\mathrm{P}$ represents a percentage, $\mathrm{N}$ is types or sub-types of cohesive devices, and $\mathrm{T}$ is the total cohesive device used by the students. Therefore, the above table shows the numerical results of cohesive devices used by the six participants in argumentative writing after counting the percentage by using the formula. From the Table, it can be seen that reference is the predominant cohesive device used by the students: 166 (57.44\%). In other words, more than half of the cohesive devices used by the students were reference. In order to obtain more detail on why some devices are more frequently used while others are not, the researcher presents the tables below to show in detail the usage of cohesive device per item.

\section{Students' usage of references}

The students' usage of reference was analysed according to the total number of cohesive devices used, and also the number of references used. The result is shown in Table 2 below. 
Table 2. Students' usage of references

\begin{tabular}{|c|c|c|}
\hline Total cohesive devices used & \multicolumn{2}{|c|}{ Reference use } \\
\hline \multirow{2}{*}{289} & $\mathrm{~N}$ & $\%$ \\
\cline { 2 - 3 } & 166 & $57.44 \%$ \\
\hline
\end{tabular}

The table above shows that, in total, 289 cohesive devices were used in the argumentative essays written by the six students. The $\mathrm{N}$ symbol shows that there are 166 references $(57.44 \%)$ used by the students. In other words, more than half of cohesive devices, both grammatical and lexical, used by the students were grammatical cohesive devices.

\section{Students' usage of demonstrative pronoun references}

The researcher then indicates how frequently the students used demonstrative reference by percentage in the following table;

Table 3. Students' usage of demonstrative pronoun references

\begin{tabular}{|c|c|c|c|}
\hline Total & Demonstrative devices used & Number of devices used & $\%$ \\
\hline \multirow{3}{*}{96} & the & 57 & $57 \%$ \\
& that & 17 & $17.70 \%$ \\
& this & 18 & $18.75 \%$ \\
& these & 1 & $1.04 \%$ \\
\hline
\end{tabular}

The table above shows that $57 \%$ of the students used demonstrative reference, which is the most predominant cohesive device of this type. Moreover, it is shown that the incidence of the students' use of references that and this are $17.70 \%$ and $18.75 \%$ respectively (see Table 3 ). The demonstrative device The is used more frequently than any others and constitutes more than half of the total percentage number of the reference devices used (57\%). Such a phenomenon occurred particularly because the exophoric demonstrative usage of 'the' is used excessively in students' writing.

Students' usage of personal pronoun references

The total number of students' usage of personal references and the corresponding number of all personal devices used are shown in the table below:

Table 4. Students' usage of personal pronoun reference

\begin{tabular}{|c|c|c|c|}
\hline Total & Personal devices use & Number of devices & $\%$ \\
\hline \multirow{6}{*}{63} & I & 6 & $9.5 \%$ \\
& they & 6 & $9.5 \%$ \\
we & he & 3 & $4.8 \%$ \\
& it & 1 & $1.5 \%$ \\
& my & 22 & $35 \%$ \\
& their & 4 & $6.3 \%$ \\
& her & 10 & $15 \%$ \\
his & 1 & $1.5 \%$ \\
its & 1 & $1.5 \%$ \\
& & 5 & $7.9 \%$ \\
\hline
\end{tabular}


From the results provided above (Table 4), it is clear that students widely used the personal reference cohesive device it (35\%). It is also noticed, however, that the students' usage of the other personal references was less than $10 \%$. Moreover, it can also be seen that the students did not use some other personal references at all, such as mine, theirs, ours, yours, and hers. It seems clear from the foregoing analysis that the students did not use those personal references at all, and there may be specific reasons for this. First, it might reflect the fact that the most students were comfortable using the third person to make writing more objective and authoritative. It might also show that the students were taught by their lecturer to use the third person pronoun as using the third person rather than first person is one of the characteristics of academic writing, where it is suggested avoiding the use of personal reference (Swales, 1990).

\section{Students' usage of conjunctions}

The total number of cohesive devices used by the participants and the corresponding conjunctions used are shown in the table below:

Table 5. Students' usage of conjunctions

Total cohesive devices used Conjunction se

\begin{tabular}{|c|c|c|}
\hline \multirow{2}{*}{289} & $\mathbf{N}$ & $\mathbf{\%}$ \\
\cline { 2 - 3 } & 89 & $30.80 \%$ \\
\hline
\end{tabular}

The result above shows that the usage of conjunctions (30.80\%) is lower than the usage of references $(57.44 \%)$.

\section{Students' usage of additive devices}

The table below reveals the number of all additive cohesive devices used by the students concerning the total number of the additive cohesive devices.

Table 6. Students' usage of additive devices

\begin{tabular}{|c|c|c|c|}
\hline Total & Additive use & Number of additive & $\%$ \\
\hline \multirow{4}{*}{59} & and & 36 & $61 \%$ \\
& or & 2 & $3.4 \%$ \\
& also & 1 & $1.7 \%$ \\
& furthermore & 2 & $3.4 \%$ \\
& for example & 4 & $6.8 \%$ \\
& for instance & 1 & $1.7 \%$ \\
& on the other hand & 1 & $1.7 \%$ \\
& besides & 3 & $5 \%$ \\
& moreover & 2 & $3.4 \%$ \\
\hline
\end{tabular}

The result shows that the highest frequency in using an additive conjunction in high-achieving students' argumentative essays is achieved by the device and (61\%). Furthermore, even if the various devices such as or, also, furthermore, for example, for instance, on the other hand, besides, moreover, in addition were used to express addition, students seem to prefer using the device and in order to fulfil its function of addition. 
Students' usage of adversative cohesive devices

The total number of adversative cohesive devices used and the number of each device used are revealed in the following table:

Table 7. Students' usage of adversative cohesive devices

\begin{tabular}{|c|c|c|c|}
\hline Total & Adversative Devices Used & Number of Devices & $\%$ \\
\hline \multirow{4}{*}{14} & however & 5 & $35.70 \%$ \\
& but & 4 & $28.60 \%$ \\
& despite & 3 & $21.42 \%$ \\
& although & 2 & $14.29 \%$ \\
\hline
\end{tabular}

The result above shows that the usage of devices however and but $(35.70 \%$ and $28.60 \%$ respectively) to express contrast are the most predominant. Furthermore, the students' usage of other contrastive devices seems to be relatively low, as the usage of despite (21.42\%), although (14.29\%), and nevertheless (7.14\%) demonstrates.

Students' usage of causal cohesive devices

The analysis of the students' causal cohesive devices is shown in the following table, by presenting the total number of causal devices used and the corresponding number for each causal device used.

Table 8. Students' usage of causal cohesive devices

\begin{tabular}{|c|c|c|c|}
\hline Total & Causal device used & Number of devices used & $\%$ \\
\hline \multirow{4}{*}{12} & resulting in & 1 & $8.33 \%$ \\
& therefore & 4 & $33.33 \%$ \\
& due to & 2 & $16.66 \%$ \\
& consequently & 2 & 16.665 \\
& as & 1 & $8.33 \%$ \\
& since & 1 & $8.33 \%$ \\
\hline
\end{tabular}

The result shows most frequent usage of the causal cohesive device is therefore $(33.33 \%)$. It would appear that the students have adequately mastered the usage of the device therefore to express result. However, students might not be familiar with other causal cohesive devices such as due to, consequently, as, since and hence, which appeared merely under $20 \%$ of the total number of causal cohesive device usage. This lack of familiarity may be because they have not been taught to use a variety of cohesive devices to refer to causal relation.

Students' usage of temporal cohesive devices

The table below represents the number of each temporal device used and the total number of temporal cohesive devices used by the students.

Table 9. Students' usage of temporal cohesive devices

\begin{tabular}{|c|c|c|c|}
\hline Total & Temporal device used & Number of devices used & $\%$ \\
\hline \multirow{2}{*}{10} & first & 2 & $20 \%$ \\
& second & 1 & $10 \%$ \\
\hline
\end{tabular}




\begin{tabular}{|c|c|c|}
\hline last & 1 & $10 \%$ \\
overall & 1 & $10 \%$ \\
in conclusion & 3 & $30 \%$ \\
to conclude & 1 & $10 \%$ \\
to sum up & 1 & $10 \%$ \\
\hline
\end{tabular}

The results show that students' usage of the in conclusion device (30\%) to express conclusion is relatively common compared to other conclusive devices, such as overall (10\%), to conclude (10\%), and to sum up (10\%). The usage of the temporal devices first (20\%), second (10\%), and last (10\%) rarely appeared in the students' essays.

Students' usage of lexical cohesive devices

In this section, the researcher explains the students' production of lexical devices in their argumentative essays. The researcher also shows which of the lexical cohesive devices are used. In relation to each of the lexical cohesive devices used, the researcher found the following results:

Table 10. Lexical cohesive devices

\begin{tabular}{|c|c|c|}
\hline Total cohesive devices used & \multicolumn{2}{|c|}{ Lexical cohesive use } \\
\hline \multirow{2}{*}{289} & $\mathrm{~N}$ & $\%$ \\
\cline { 2 - 3 } & 34 & 11.76 \\
\hline
\end{tabular}

The above table represents the number of cohesive devices employed by the participants and the corresponding number of lexical cohesive devices used. The result shows that the usage of lexical cohesive devices (11.76\%) is lower than the usage of grammatical cohesive devices (80.24\%).

Table 11. Students' usage of repetition cohesive devices

\begin{tabular}{|c|c|c|c|}
\hline \multirow{3}{*}{ Total } & Type of reiteration & Number of reiterations used & $\%$ \\
\hline \multirow{3}{*}{289} & Repetition & 8 & $2.77 \%$ \\
\cline { 2 - 4 } & Synonym & 13 & $4.50 \% \%$ \\
\cline { 2 - 4 } & Meronyms & 9 & $3.11 \%$ \\
\cline { 2 - 4 } & Superordinates & 4 & $1.38 \%$ \\
\hline
\end{tabular}

The table above shows that the most frequent reiteration used by students is synonym $(4.50 \%)$, while the remaining devices are repetition, general words and superordinates, at $2.77 \%, 3.11 \%$ and $1.38 \%$ respectively. This is seen in the students' argumentative essays as follows:

Usage of synonyms

The following examples are students' usage of synonyms as taken from the argumentative essays written by the students.

1. Student essay A: 'Online platform'- 'Social Media' (lines 18 and 21); a big change- crucial change (line 3 and 24).

2. Student essay C: 'stand point'-'perspective' (lines 3 and 17).

3. Student essay D:'an excellent platform'- 'perfect platform' (lines 14 and 29);'useful features'-'good features' (lines 4 and 10);'a suitable platform for 
online shopping'- 'the easiness to connect people in Facebook creates a wide opportunity for the online base shopping' (lines 28-29 and 21-22).

All examples of the usage of synonyms in students' essays above show that the students were aware of using these to achieve cohesion in writing. For example, student A, instead of repeating the same words, 'online platform', used 'social media' as a synonym. This result is also shown in research conducted by Alarcon (2013) where the participants also used synonyms more frequently rather than other lexical cohesive devices; repetition, meronyms, and superordinates.

\section{Usage of Repetition}

The following are examples of students' usage of repetitions, as taken from their argumentative essays.

1. Student essay A: opinions (lines 15 and 16), people (lines 17 and 18).

"Furthermore, people can easily gather and find groups in this online platform, making it possible for a massive amount of information to spread easily to the quality of people throughout the country".

2. Student essay B: status (lines 7 and 9), addiction (lines 17 and 18).

"Most people have hundreds and even thousands of friends with many of them updating their status every day on their Facebook accounts which takes much time to spend to keep up with his or her friends. More time will be needed if some status can attract attention and drive the user to start chatting by replying comments and giving likes each other".

From the passages above, it is seen that although the students gained a score of $\mathrm{A}$ in the argumentative essay class, it appears that they still used repetitions excessively. As overused repetition sometimes leads to redundancy (excessive or unnecessary) and affects writing quality, it is suggested that students avoid repeating the same words and use synonyms, instead (Reynolds, 1995). However, it is still appropriate to use repetition to make two sentences coherent (Hasan, 1984). For example;

"The little girl asked her father for ice cream. He asked her mother, and she gave them some (Reynolds, 1995:188)"

According to Nordquist (2016:1), it is necessary to repeat 'keywords in a paragraph for achieving cohesion'.

\section{Usage of meronyms}

The following examples demonstrate students' usage of meronyms taken from the argumentative essays they wrote. As has been explained in Chapter 2, meronyms are used to impart examples of a concept as shown in the extracts below:

1. Student essay B: Online games such as poker, billiard and throne rush are the examples of favourite games in Facebook played individually or in team requiring long enough time for one round to finish (lines 14-16).

2. Student essay C: The use of Facebook could catalyse for developing our international communication skills such as the skills of self-disclosure and self-identity (lines 5-6). 
From the passages extracted from the students' essays above, it appears that they seem aware that in order to achieve cohesion they can use meronyms. This phenomenon also occurred in a study conducted by Alarcon (2013), where a group of highly rated students used meronyms (11.02\%) to achieve cohesion.

Usage of Superordinates

The following are examples of usage of the superordinate, taken from the argumentative essays written by the students.

1. Student essay A: Social media platform- Facebook (lines 18-20).

"One profound change encouraged by Facebook was the Egyptian

Revolution, which was ignited by a movement, and by discussion, on this social media platform".

2. Student essay B: Social media application- Facebook (line 3).

"One way to do this is to use Facebook, which is the most popular

social media application that can be installed on the portable devices such as laptops and smartphones".

The participants in the current study mostly used this technique of superordinates to achieve cohesion. In one of the examples shown in the students' essays above, the word 'Facebook' refers back to 'Social media'. It seems that most of them were aware of the usage of the cohesive device of this type-superordinate in order to achieve cohesion in their writing.

\section{Discussion of interview data}

Students' understanding of the usage of cohesive devices in argumentative essays

The interview data regarding students' understanding of the usage of cohesive devices in argumentative essays revealed important findings. First, it was found that not all of the students know the term cohesive devices. This can be seen in the following extracts from the interviews with student A and B:

"I have never heard the term cohesive devices (Student A: translated version)".

"I am not sure what these cohesive devices mean (Student B: translated version)".

However, when the interviewer tried to give clues and examples, some students could then mention the examples and understand the cohesive devices that the interviewer had referred to:

"Oh I see this is a kind of connector which functions to connect one sentence to another sentence and one paragraph to another one. For instance, however, but, and, therefore and so on" (Student A: translated version).

From the above statement, it could be seen that although some students do not know what cohesive devices are, they can understand their basic functions. This is because, in their writing argumentative essay class in the third semester of college, they acquired this concept under the term connector. Furthermore, when the students were asked what other types of cohesive devices they knew, they were only familiar with conjunctions. In fact, conjunctions are only one type of cohesive 
devices. It can be seen in the literature review above that according to Halliday and Hassan (1969), cohesive devices are divided into two main types, namely grammatical and lexical, and conjunctions fall into the category of grammatical cohesive devices. This can be seen in the following extract from student C:

"So far, what I know about connector is only conjunctions, and I do not know if there is another type of connector, but conjunction (Student C: translated version)".

All of the above statements led the researcher to the thought that if students are not explicitly aware of other types of cohesive device, how effectively can they use these devices? As demonstrated in the results from their argumentative writing, they successfully used various types of cohesive devices. This phenomenon raised the question of how they could use cohesive devices if they did not know what other types of cohesive device existed. One explanation may be that they learn from other good practice:

"The way I learn to use cohesive devices or connectors is by reading other good essays that I got online. I found other types of cohesive devices on other essays and I did not realise that they are cohesive devices. What I thought was they were only vocabulary words that are commonly used in writing argumentative essays (Student C: translated version)".

On the other hand, some other students are aware of different types of cohesive devices and their functions, as they had only taken external academic classes at an English language centre:

"When I knew that I would get an argumentative writing essay class at the college, I realised that I needed to have extra class to support my knowledge in writing academically. And this class is very helpful to give more explanations in terms of what I should do in academic writing and gaining more practice (Student B: translated version)".

The above statement confirms that the writing class that they had during the third semester was not enough to develop their writing skills. This led them to take extra classes to support their study, and reading the essays of others is one way that some of the students learned writing, and, in particular, familiarised themselves with cohesive devices.

Students' perceptions of generating good writing quality

All of the students agreed that it is important to use connectors or cohesive devices to achieve coherence in writing. This can be seen in the following extracts from two students, A and F:

"I used cohesive devices to connect not only sentences but also paragraphs of an essay (Student A: translated version)'.

This is in line with the theories of Halliday and Hassan (1976), Alarcon and Morales (2011), Wahiba (2017), and Ghasemi (2013), which argue that employing cohesive devices is an important way to gain coherence in writing. Additionally, it was revealed in the interviews that students feel that by using more cohesive devices 
in writing to achieve coherence, they can more easily connect the ideas in a text and, at the same time, demonstrate their competence in creating good writing:

"What I feel is that using cohesive devices helps me to construct my writing ideas and make it readable to the readers. In fact, by making readers easily following my ideas in my writing gives me better score in writing class (Student F: translate version)".

Furthermore, three of the six students revealed a further insight regarding awareness of the usage of cohesive devices to generate a good piece of writing. They stated that the usage of cohesive devices enables readers to easily follow what a writer is trying to convey through the essay.

"If we do not use connectors or cohesive devices to make readers easily understand the storyline of the texts, readers will be confused to see the flow of the story or ideas that writers are trying to convey and they will end up not understand the essay (Student D: translated version)".

However, the student argued that cohesive devices are not determining factors in achieving good writing quality. He stated that essays could be considered as having high-quality writing if they contain linguistic features which are related to sophisticated language and the difficulty of the text.

"To me cohesive devices are only one way to read texts easily and it is not associated with writing quality. The more cohesive devices, the easier to read the text. And in my opinion, there is no relationship between number of cohesive devices and high essay scores gained by us-the high-achieving students in writing argumentative essays (Student F: translated version)".

This voice directly supports previous studies, which found that cohesive devices are not determining factors in a high quality of writing (Dastjerdi and Samian, 2011; McNamara et al., 2010). Therefore, although cohesive devices are perceived to be important by all of the students to achieve writing coherence, some argue that cohesive devices are not determining factors in enhancing writing quality; rather, sophisticated grammar and lexical diversity is more important.

Higher-Achieving Students' Perceptions of Supporting Programmes for the Teaching and Learning of Argumentative Essays

In general, the students suggest the most challenging part of creating good quality writing is finding the idea.

"For me, the most difficult part in writing an argumentative essay is getting the ideas. Even though I got the A score at the end of the class, finding ideas is my truly greatest problem, and I believe this is what my other friends (lower-achieving students) were suffering from when they tried to begin writing argumentative essays (Student $F$ : translated version)".

Another problem faced by the students is generating a piece of writing with good coherence; 
"In my opinion, the most challenging in writing an argumentative essay is putting the ideas together very well. Somehow, I found it hard when I need to write with a good coherence (Student C: translated version)".

The two problems above are perceptions also stated by the other students; even though they gained A scores in class, high-achieving students still find it challenging to create argumentative essays due to a lack of ideas and ability to present ideas coherently.

To understand how students deal with these issues, the researcher asked how they approach these kinds of circumstances. Most of the students claim to use similar methods, which are reading the essays of others, peer reviews and using cohesive devices.

"Reading strategies are actually recommended by my English tutor when I leaned writing academic at the English centre. By reading others' good pieces of writing I could understand not only how good writers write by using academic vocabulary and grammar, I could also see other people's ideas and use them in my own writing" (Student E: translated version).

The researcher was interested to know that all of the students share a similar perspective: to improve the quality of writing, a writer is required to read more frequently. This was also seen in a study by Plakans (2009), which examined the use of twelve English as a Second Language writers' reading strategies in an integrated writing task through analyses of think-aloud protocols and interviews. The study also showed that students who composed better essays employed more effective reading strategies. This has also been confirmed by studies, including those by Spivey and King, 1989; Kennedy, 1985, and Watanabe; 2001, that there is a strong correlation between frequent reading and good writers.

Furthermore, it can be seen from students $\mathrm{A}$ and $\mathrm{E}$ above that both believe that a reading strategy is one of the best ways to deal with a lack of ideas, which can be the first problem for students in creating good essays. This can even improve writing quality. Therefore, it is suggested that lower-achieving students apply the same strategy, namely reading extensively, like their high-achieving peers. As one student admitted:

"It will be helpful if the teacher or the lecturer of writing integrated reading and writing because these two skills are related to each other" (Student D: translated version).

The last method that the researcher found related to students' difficulty in producing argumentative writing with a good coherence is using cohesive devices. As can be seen from student F, using cohesive devices can help the student to increase the coherence of their argumentative essays:

"In my opinion, using cohesive devices or connectors is one the best ways I used to increase coherence of my argumentative writing. Cohesive devices help me to connect the ideas I have, as so the readers can easily read my writing, and I guess that is why my lecturer gave me a good score (Student F: translated version)". 
Although some previous studies (Meiso, 2010; Jafarpur, 1991) show that cohesive devices do not help to improve writing quality, some of the students of this study, represented by student F, stated that utilising cohesive devices is useful in improving their writing coherence and, at the same time, enhance their writing quality. This finding is in line with the results of studies conducted by Witte and Fraignley (1981) and McCauley (1985).

\section{CONCLUSIONS}

This study also revealed some reasons why some cohesive devices are more frequently used while some others are not. The first reason was familiarity or lack of familiarity in using the cohesive devices. Some cohesive devices did not appear at all in the students' argumentative writing, such as ellipsis and substitution. This is because the students are presumably not familiar with using these devices in a composition. This was also found in some previous studies such as those by Rohim (2010) and Azzuouz (2009). Secondly, in terms of the use of lexical cohesive device by the students in their argumentative essays, results showed that in order to achieve cohesion, they used synonyms more than other sub-types of lexical cohesive devices. This result was also found in a study by Alarcon (2013), where the participants used synonyms more frequently than the other lexical cohesive devices of repetition, meronyms, and superordinates. The usage of synonyms is viewed as a feature of good writing in a study by Liu and Zhong (2014), who investigated L2 and L1 use of synonyms. The higher-rated writing produced by L2 and L1 writers was shown to have more use of synonyms. Third, a particular device such as the more frequently appeared compared to other devices, as the functions not only as a cohesive device connecting sentences, but also as an article. Therefore, due to the two functions of the, it became the most frequently used cohesive device in argumentative essay written by the high-achieving students.

This finding aroused the researcher's curiosity. From the interview data, he found that this seeming lack of knowledge can be explained because students had learned a range of conjunctions from extensively reading other people's writing, without explicitly learning the linguistics terms for these devices. What they believed was that by reading other people's of writing they could deal with issues they encountered during the writing process, such as difficulty in finding ideas, vocabulary use, grammar, and connecting ideas. Moreover, regarding the students' conceptions of producing good writing quality, all agreed that it is necessary to use links or cohesive devices to achieve coherence in writing. This is in line with the theories of Halliday and Hassan (1976), Alarcon and Morales (2011), Wahiba (2017), and Ghasemi (2013), which argue that employing cohesive devices is an important way to gain coherence in writing. Furthermore, they contend that using more cohesive devices in compositions can help the students connect the ideas in a text and, at the same time, show their competence in generating good pieces of writing.

\section{REFERENCES}

Alarcon, J. (2013). Lexical cohesion in students argumentative essay among a select group of Filipino college students. i-Manager's Journal on English Language Teaching, 3(2), 43-52. 
Alarcon, J. B. \& Morales, K. N. S. (2011). Grammatical cohesion in students argumentative essay. International Journal of English and Literature, 2(5), 114-127.

Carter, R (2002) Working with Texts: A Core Introduction to Language Analsysis. New York: Routledge.

Celce-Murcia, M. \& Olshtain, E. (2000). Discourse and context in language teaching: A guide for language teachers. Ernst KlettSprachen.

Dastjerdi, H. V. \& Samian, S. H. (2011). Quality of Iranian EFL learners' argumentative essays: Cohesive devices in focus. Mediterranean Journal of Social Sciences, 2(2), 65-76.

Enkvist, N. E. (1990). Seven problems in the study of coherence and interpretability. Coherence in writing: Research and pedagogical perspectives, 9-28.

Ghasemi, M. (2013).An investigation into the use of cohesive devices in second language writings. Theory and Practice in Language Studies, 3(9), 1615.

Halliday, M. A. and Hasan, R. (1969). Cohesion in. English, Longman, London.

Hasan, R. (1984). Coherence and cohesive harmony. Understanding reading comprehension: Cognition, language and the structure of prose, 181219.

Hoey, M. (1991) Patterns of Lexis in Texts. Oxford: Oxford University Press.

Jafarpur, A (1994) 'Cohesiveness and as a basis for evaluating comparisons', System, 19 (4), 459-465).

Kennedy, M. L. (1985). The composing process of college students writing from sources. Written Communication, 2(4), 434-456.

Lopez-Fernandez, O. \& Molina-Azorin, J. F. (2011). The use of mixed methods research in interdisciplinary educational journals. International Journal of Multiple Research Approaches, 5(2), 269-283.

McNamara, D. S., Crossley, S. A. \& McCarthy, P. M. (2010). Linguistic features of writing quality. Written Communication, 27(1), 57-86.

Munsell, P \& Clough, M. (1984). A practical guide for advanced writers in English as a second language. Macmillan publishing company, New York.

Nordquist, R. (2016). Cohesion Strategies: Repeating Key Words and Structures. [online] Available at: https://www.thoughtco.com/repeating-key-wordsand-structures-1690555 [Accessed 19 August 2017].

Plakans, L. (2009). The role of reading strategies in integrated L2 writing tasks. Journal of English for Academic Purposes, 8(4), pp.252-266.

Podis, J. M \& Podis, L.A. (1996). Rethinking writing. Boston, Allyn and Bacon.

Raimes, A. (2002). Keys for Writers: A Brief Handbook $3^{\text {rd }}$. Haughton Mifflin, Boston. 
Reid, J. (1992). A computer text analysis of four cohesion devices in English discourse by native and nonnative writers. Journal of Second Language Writing, 1(2), 79-107.

Reynolds, D. W. (1995). Repetition in nonnative speaker writing: More than quantity. Studies in Second Language Acquisition, 17(2), 185-209.

Rohim, A. (2010). Cohesion analysis on The Jakarta Post's editorial.

Spivey, N. N. \& King, J. R. (1989). Readers as writers composing from sources. Reading Research Quarterly, 7-26.

Swales, J. (1990). Genre analysis: English in academic and research settings. Cambridge University Press.

Tashakkori, A. \& Teddlie, C. eds. (2010). Sage handbook of mixed methods in social \& behavioral research. Sage.

Tate, G., Corbett, E., \& Myers, N. (1994). The writing teacher's sourcebook. Oxford University Press, New York.

Wahiba, K. (2017). The Use of Cohesive Devices in Paragraph Writing Case study: Second Year LMD students at Biskra University (Doctoral dissertation).

Watanabe, Y. (2001). Read-to-write tasks for the assessment of second language academic writing skills: Investigating text features and rater reactions (Doctoral dissertation, University of Hawaii at Manoa).

Witte, S.P Fraigley, L (1981) 'Coherence, cohesion, and writing quality', College composition and commnunication, 32 (2), 189-204. 